\title{
Mapping and characterization of quantitative trait loci affecting resistance against second- generation European corn borer in maize with the aid of RFLPs
}

\author{
CHRIS C. SCHÖN, MICHAEL LEE†, ALBRECHT E. MELCHINGER*, \\ WILBUR D. GUTHRIE $† \$$ \& WENDY L. WOODMAN $\dagger$ \\ Institute of Plant Breeding, Seed Science and Population Genetics, University of Hohenheim, P.O. Box 700562, W-7000 \\ Stuttgart 70, Germany, †Department of Agronomy, lowa State University, Ames, IA 50011 and $\ddagger$ USDA-ARS, Ankeny,
} IA 50011, U.S.A.

\begin{abstract}
The European corn borer (Ostrinia nubilalis Hübner) is an important pest in the global production of maize (Zea mays L.). In this study, we mapped and characterized quantitative trait loci (QTLs) significantly affecting resistance against second-generation European corn borer (2ECB) and plant height with the aid of RFLP markers. A total of $300 \mathrm{~F}_{3}$ lines derived from cross B73 (susceptible) $\times$ B52 (resistant) were assayed for their parental $F_{2}$ genotype at 87 RFLP loci. Field data on plant height and resistance against $2 \mathrm{ECB}$ were collected for the $300 \mathrm{~F}_{3}$ lines, the parents and the $\mathrm{F}_{2}$ generation at two sites, Ames and Ankeny, IA, USA. Resistance was assessed by measuring the damage of stalk tissue (tunnel length) caused by severe artificial infestation with 2ECB larvae. Genotypic variances among $F_{3}$ lines were highly significant for tunnel length and plant height, but genotype by location interactions were significantly different from zero only for plant height. Heritabilities were intermediate $(0.63)$ for tunnel length but high $(0.87)$ for plant height. The genotypic correlation between the two traits was 0.29 . The method of interval mapping was used for localization of QTLs and estimation of their genetic effects. In the combined analysis across locations, genomic regions significantly affecting resistance against $2 \mathrm{ECB}$ were found on chromosome arms $I S, I L, 2 S, 2 L, 3 L, 7 L$ and $10 L$. Genomic regions on $I S, 3 L$ and $9 L$ significantly affected plant height. Results were largely consistent across locations. Different types of gene action were found for the putative QTLs for both traits. For tunnel length a total of 38 per cent of the phenotypic variance was explained by simultaneous mapping of the seven putative QTLs. The three putative QTLs for plant height explained 63 per cent of the phenotypic variance. On $3 L$, evidence was found for an interaction of genes conferring resistance to $2 \mathrm{ECB}$ and plant height. Significant digenic epistasis was detected for one pair of marker loci.
\end{abstract}

Keywords: interval mapping, $O$. nubilalis Hübner, quantitative trait loci, resistance, RFLPs.

\section{Introduction}

Most traits of agronomic importance show continuous variation owing to polygenic inheritance and the influence of environmental factors. Trait expression is regulated by a great number of genes, which differ in magnitude and direction of their effects and interact with each other. In the past, quantitative geneticists used biometrical methods such as generation means

*Correspondence. analysis (Mather \& Jinks, 1971) to estimate parameters of gene action for quantitative traits. A limitation of these methods is that they do not yield information on genes as separate entities but only on the sum of their effects. In addition, they are constrained by a number of assumptions, which are frequently not satisfied.

Thoday (1961) suggested the use of Mendelian markers to map the genomic position of quantitative trait loci (QTLs). Practical applications of this approach, however, were limited because of a lack of suitable markers. Advances in molecular biology 
during the past decade, such as the development of restriction fragment length polymorphisms (RFLPs) as a new class of molecular markers, have made it possible to overcome this problem. Genetic linkage maps well saturated with molecular markers have been established for a number of agriculturally important crops such as maize (Coe et al., 1990), tomato (Bernatzky \& Tanksley, 1986), brassica (Slocum et al., 1990), soybean (Keim et al., 1990) and barley (Graner et al., 1991). A further improvement was the development of statistical methods and computer packages handling linkage analyses between marker loci and QTLs for experimental populations used by plant breeders (Lander \& Botstein, 1989; Knapp et al., 1990). As a consequence, it seems possible to dissect complex quantitative traits at least partly into their underlying Mendelian components. Significant associations of molecular markers with QTLs have been reported for yield, quality traits and insect resistance in interspecific crosses of tomato (Paterson et al., 1991; Nienhuis et al., 1987). In maize, QTLs for yield, yield components, abiotic stress and morphological characters have been described (Edwards et al., 1987; Stuber et al., 1987; Abler et al., 1991; Reiter et al., 1991).

Maize is an excellent species for QTL analyses. A large number $(>500)$ of RFLP markers already mapped in the maize genome is publicly available. In contrast to many other crops, where interspecific crosses are used to overcome the lack of polymorphism, a sufficiently large number of RFLPs can be found in intraspecific crosses. As shown by Abler et al. (1991), there is considerable genetic variation for quantitative traits in elite U.S.A. maize germplasm. If QTLs can be identified in commercially-used inbreds, the transfer of results into applied plant breeding programmes should be facilitated.

In this study, we characterized QTLs for resistance against the second generation of the European corn borer (ECB) (Ostrinia nubilalis $\mathrm{H}$.) in maize (Zea mays L. with the aid of RFLP markers. ECB is a major pest of maize in Europe and North America. In the corn belt of the U.S.A., the ECB usually has two generations. First-generation larvae (1ECB) feed on leaf blades during the whorl stage of the maize plant, while second-generation larvae (2ECB) attack the plant at or shortly after anthesis and feed on sheath collars and within the stalk and shank. Extensive yield losses result from weakened plants, plant lodging, dropped ears and increased susceptibility to fungal diseases (North Central Regional Extension Publication, 1989). In susceptible single-cross hybrids, Scott $e t$ al. (1967) observed an average yield reduction of 12 per cent from 2ECB infestation. Guthrie et al. (1975) reported yield losses of up to 35 per cent under heavy infestation of $2 \mathrm{ECB}$ larvae.
Resistance against the two ECB generations is conditioned by independent mechanisms, both with quantitative inheritance and mainly additive gene action (Guthrie \& Russell, 1989). Against 1ECB, resistance has been relatively easy to identify and quite a large number of highly resistant inbred lines have been developed. In contrast, breeding for resistance against 2ECB has proved difficult. While backcross breeding appeared to have little effect in improving the level of resistance owing to the putatively high number of genes involved, recurrent selection resulted in a negative correlated response for other agronomically important traits such as yield (Guthrie \& Russell, 1989). Additionally, breeding strategies are impeded by the extremely time- and labour-consuming procedures for screening field materials.

Objectives of our study were to: (i) determine the number and chromosomal location of QTLs conferring resistance against $2 \mathrm{ECB}$ using RFLP mapping; (ii) examine the size of genetic effects and the type of gene action at these QTLs; and (iii) evaluate the environmental stability of associations between RFLP loci and QTLs.

\section{Materials and methods}

\section{Plant materials}

Two homozygous U.S.A. maize inbred lines, B73 and B52 (subsequently also referred to as $P_{1}$ and $P_{2}$ ), were used as the parental material. B52 is one of the few available sources of resistance against 2ECB. In contrast, $\mathrm{B} 73$ is highly susceptible to damage by $2 \mathrm{ECB}$ but was widely used as a parent of commercial hybrids grown in the corn belt of the U.S.A. because of its excellent combining ability for grain yield. In the 1988 breeding nursery at Ames, IA, randomly chosen $\mathrm{F}_{2}$ plants from cross $\mathrm{B} 73 \times \mathrm{B} 52$ were self-pollinated to produce $300 \mathrm{~F}_{3}$ lines.

\section{RFLP assays}

From each of the $300 \mathrm{~F}_{3}$ lines, 10 seedlings were grown in the greenhouse. For genotyping of the parental $F_{2}$ plant, equal quantities of leaf tissue from the 10 seedlings were harvested and bulked. Laboratory procedures for RFLP assays were performed as described by Lee et al. (1989). A total of one cDNA and 86 genomic maize clones with single-copy hybridization patterns was selected from collections of mapped clones available from Brookhaven National Laboratory (Burr et al., 1988), the University of Missouri, Columbia (Coe et al., 1990) and Native Plants Inc. (Weber \& Helentjaris, 1989) to provide a uniform coverage of the genome. 


\section{Agronomic trials}

The $300 \mathrm{~F}_{3}$ lines, both parents and their $\mathrm{F}_{2}$ generation were evaluated in a simple $17 \times 18$ rectangular lattice design. Parents and the $F_{2}$ generation were included as duplicate entries. Plots consisted of two hills on 76.2 $\mathrm{cm}$ centres. Six kernels per hill were hand-planted and after germination thinned to three plants to reach a total of six plants per plot. The experiment was conducted in 1989 at two sites, Ames and Ankeny, located in central lowa.

At anthesis when the maize plants had reached their full height, artificial infestation was carried out with a calibrated number of 2ECB larvae. The larvae were placed on the leaf axils above and below the primary ear. Infestation was repeated on four successive days to reach a total infestation level of 600 larvae per plant. Thus, escapes could safely be precluded. Damage by 2ECB was assessed approximately 60 days after infestation. The stalk of each of the six plants per plot was longitudinally split from soil level to the first node above the primary ear and the length of the stalk tissue damaged by feeding of $2 \mathrm{ECB}$ larvae (tunnel length) was recorded in centimetres. Parallel tunnels were counted only once. Plant height was measured at flowering time in centimetres from soil level to the axil of the flag leaf. Tunnel length per unit plant height was calculated on the basis of entry means by dividing tunnel length by plant height.

\section{Data analysis}

Lattice analyses of variance were performed on field data from each location using the plot means calculated from individual plant measurements for each trait. Adjusted entry means and effective error mean squares were used to compute the combined analysis across locations. The sums of squares for entries with 305 degrees of freedom (d.f.) were subdivided into the variation among $F_{3}$ lines (299 d.f.) and orthogonal contrasts among the means of the four generations $\left(\mathrm{P}_{1}\right.$, $\left.P_{2}, F_{2}, F_{3}\right)$. A corresponding subdivision was conducted on the entry by location interaction sums of squares. Normality of adjusted entry means from individual locations and of entry means across locations was checked using the $W$-test described by Shapiro \& Wilk (1965). Student's $t$-test was used to compare means of homozygous marker classes (Snedecor \& Cochran, 1967).

Estimates of variance components for $\sigma^{2}$ (error variance), $\sigma_{g l}^{2}$ (genotype-location interaction variance) and $\sigma_{g}^{2}$ (genotypic variance) of $\mathrm{F}_{3}$ lines and their standard errors (S.E.) were calculated as described by Searle (1971). Homogeneity of variances for marker classes was tested using Bartlett's test criterion as described by Snedecor \& Cochran (1967).

Heritabilities $\left(h^{2}\right)$ on a progeny-mean basis were estimated with the formula presented by Hallauer \& Miranda(1981):

$h^{2}=\frac{\hat{\sigma}_{g}^{2}}{\hat{\sigma}^{2} / r l+\hat{\sigma}_{g l}^{2} / l+\hat{\sigma}_{g}^{2}}$,

where $r=$ number of replications and $l=$ number of locations. Exact 90 per cent confidence intervals on $h^{2}$ were calculated according to Knapp et al. (1985). Phenotypic $\left(\mathrm{r}_{p}\right)$ and genotypic $\left(\mathrm{r}_{g}\right)$ correlations between tunnel length and plant height were estimated on a progeny-mean basis using standard procedures (Mode \& Robinson, 1959).

The 'effective number' $(n)$, i.e. the minimum number (Lande, 1981) of factors influencing the trait tunnel length was estimated according to Wright (1968) using the correction factor suggested by Cockerham (1986):

$n=\frac{\left(\overline{\mathrm{P}_{1}}-\overline{\mathrm{P}_{2}}\right)^{2}-\left(\hat{\sigma}_{\mathrm{P}_{1}}^{2}+\hat{\sigma}_{\mathrm{P}_{2}}^{2}\right)}{8 \hat{\sigma}_{g}^{2}}$,

where $\overline{\mathrm{P}_{1}}$ and $\overline{\mathrm{P}_{2}}$ are estimates of the mean phenotypic trait value of $\mathrm{P}_{1}$ and $\mathrm{P}_{2}$, respectively, and $\hat{\sigma}_{\mathrm{P}_{1}}^{2}$ and $\hat{\sigma}_{\mathrm{P}_{2}}^{2}$ are the estimated error variances of these means.

Marker loci were checked for deviations from Mendelian segregation ratio 1:2:1 and allelic frequency 0.5 using chi-square tests (Weir, 1990).

The mean proportion of the B73 genome was estimated for the $300 \mathrm{~F}_{2}$ genotypes as described by Paterson et al. (1991). The parental origin of each marker interval was inferred from its flanking markers. If the interval endpoints had the same genotype, the entire intervening segment was assigned the genotype of the flanking markers. If consecutive marker genotypes were different, the segment in between was assumed to comprise half of each genotype.

A linkage map for cross B $73 \times$ B52 consisting of the 87 RFLP markers was assembled using MAPMAKER (Lander et al., 1987). For declaration of linkage, a LOD $\left(\log _{10}\right.$ of the likelihood odds ratio) threshold of 3.0 and a maximum recombination frequency of 0.40 were used. If in the ordering process two orders of loci were not significantly different (LoD difference $<3.0$ ), the most likely order was chosen. Genetic distances between markers were estimated using the mapping function of Haldane (1919).

Mapping of QTLs and estimation of their genetic effects were performed according to the method of interval mapping described by Lander \& Botstein (1989) using the computer package MAPMAKER/QTL (Lincoln \& Lander, 1990). For the $F_{2}$ generation, the 
MAPMAKER/QTL program estimates genetic effects at a QTL according to the unconstrained model:

$y_{\mathrm{i}}=\mu_{\mathrm{AA}}+k_{\mathrm{i}} a+h_{\mathrm{i}} d+e_{\mathrm{i}}$.

Here, $y_{\mathrm{i}}=$ phenotypic trait value of individual $i$, $\mu_{\mathrm{AA}}=$ mean phenotypic trait value of individuals homozygous for the $A$ allele, $k_{\mathrm{i}}=$ number of $B$ alleles carried by individual $i, a=$ additive effect of the $B$ allele, $h_{\mathrm{i}}=1$ if individual $i$ is heterozygous, but 0 otherwise, $d=$ dominance effect, $e_{\mathrm{i}}=$ variation of the trait not controlled by the QTL. For further details see Lincoln \& Lander (1990).

When progeny means of $F_{3}$ lines instead of $F_{2}$ individuals are used for phenotyping, as was the case in our study, only half of the dominance effects of the $F_{2}$ plants contribute to the genotypic means of their $F_{3}$ progenies. Therefore, estimates of $d$ from MAPMAKER/ QTL were multiplied by two in our study to obtain the usual estimates of dominance effects according to the $F_{\infty}$-metric (Mather \& Jinks, 1971).

Under the assumption of the sparse map case (independent occurrences of spuriously high LOD scores) and a constrained additive model ( 1 d.f. at each locus), the appropriate LoD threshold $(T)$ for declaration of a significant QTL can be inferred from the formula given by Lander \& Botstein (1989):

$T=\frac{1}{2}\left(\log _{10}{ }^{e}\right)\left(Z_{P / M}\right)^{2}$,

with $P$ being the probability of declaring a single false QTL in the genome when $M$ marker intervals are tested. As suggested by Paterson et al. (1991) for the analysis of $F_{2}$ intercross progeny, we scanned the entire genome for significant QTLs using the unconstrained model. Significance of each putative QTL was confirmed by re-evaluating LoD scores fitting the constrained additive model $(d=0)$. In our study (with 77 marker intervals tested), presence of a putative QTL in a given genomic region was declared when the LOD score of the additive model exceeded a threshold of 2.2 , corresponding to a probability $P<0.05$ that a false positive occurs somewhere in the genome. Finally, estimates of additive and dominance effects, the total variance explained by significant QTLs and the total LOD score were obtained by fitting a model including all putative QTLs for the respective trait simultaneously.

Between pairs of marker loci significantly associated with a QTL, digenic epistatic interactions were tested. For each locus pair, the means of the nine possible genotypic classes from individual locations were weighted with their respective number of observations and subjected to a two-factor analysis of variance. The sequentially rejective Bonferroni procedure (Holm, 1979) was applied when testing epistatic effects (4 d.f.) against the epistatic effects by environment interaction
(4 d.f.). Significant epistatic effects and the epistatic effect by environment interaction were partitioned into additive $\times$ additive, additive $\times$ dominant, dominant $\times$ additive and dominant $x$ dominant contrasts. The necessary computations were performed by using PROC GLM of SAS (SAS Institute, 1988).

\section{Results}

\section{Segregation and linkage analyses}

For 18 ( 21 per cent) of the 87 marker loci assayed, the chi-square test ( 2 d.f.) revealed highly significant $(P<0.01)$ deviations from the 1:2:1 ratio expected for an $F_{2}$ population. An overall excess of heterozygotes was observed in contrast to the expected deficiency when DNA from bulked $\mathrm{F}_{3}$ leaf tissue was used to determine the genotype of the parental $F_{2}$ plant. Segregation distortion was found for all 10 chromosomes. Deviations from the expected allelic frequency of 0.5 were tested with a single degree-of-freedom chi-square test and were highly significant $(P<0.01)$ at 14 loci $(16$ per cent). Nine of them showed an excess of B73 alleles. On chromosome 4 , a segment with three linked loci (BNL15.45, UMC42 and UMC19) was distorted in favour of B52 alleles.

The proportion of the $\mathrm{B} 73$ genome ranged from 28 per cent to 80 per cent among the $300 \mathrm{~F}_{2}$ individuals (Fig. 1). The mean proportion was 50.9 per cent, which is not significantly different from the expected 50 per cent under normal Mendelian segregation.

The RFLP linkage map was in good agreement with previously published RFLP maps in maize (Burr et al., 1988; Coe et al., 1990). UMC104 was the only probe not significantly linked to one of the 10 linkage groups.

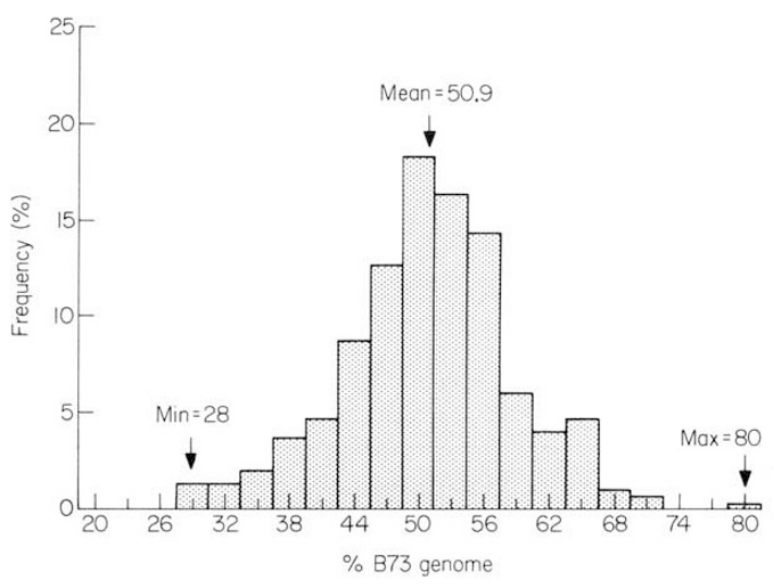

Fig. 1 Histogram for the percentage $B 73$ genome of $300 \mathrm{~F}_{2}$ individuals derived from cross $\mathrm{B} 73 \times \mathrm{B} 52$. 
For QTL mapping, it was placed on chromosome 5 in accordance with previously published maps and evidence provided by the data. The 87 markers span a map distance of $1716 \mathrm{cM}$ with an average interval length of $22 \mathrm{cM}$.

\section{Agronomic trait analyses}

Adjusted entry means from individual locations and entry means across locations followed a Gaussian (normal) distribution for both traits except at Ames, where entry means for plant height deviated significantly $(P=0.02)$ from normality. In the combined analysis across locations, means of parents B52 and B73 differed significantly $(P<0.01)$ for tunnel length but not for plant height (Table 1). As expected, tunnel length was significantly reduced in the $2 \mathrm{ECB}$ resistant parent B52 in comparison with the susceptible parent B73. Orthogonal contrasts revealed a significantly greater plant height for the $\mathrm{F}_{2}$ generation than for the parental mean $(\overline{\mathrm{P}})$, indicating substantial heterosis for this trait. Moreover, the contrast $\mathrm{F}_{2}+\overline{\mathrm{P}}-2 \overline{\mathrm{F}}_{3}\left(\overline{\mathrm{F}}_{3}=\right.$ mean of the $300 \mathrm{~F}_{3}$ lines) was significantly $(P<0.01)$ greater than zero for plant height, providing evidence for epistasis. No significant differences were found between the mean of the $300 \mathrm{~F}_{3}$ lines and the parental mean $(\overline{\mathrm{P}})$ for both traits.

Genotypic variances $\left(\hat{\sigma}_{g}^{2}\right)$ among $\mathrm{F}_{3}$ lines were highly significant $(P<0.01)$ for both traits (Table 1). Genotype-location interactions $\left(\hat{\sigma}_{g l}^{2}\right)$ were not significantly greater than zero for tunnel length but highly significant $(P<0.01)$ for plant height. However, $\hat{\sigma}_{g l}^{2}$ was considerably smaller than $\hat{\sigma}_{g}^{2}$ for both traits.

Heritability $\left(h^{2}\right)$ estimates for $\mathrm{F}_{3}$ lines were intermediate $(0.63)$ for tunnel length but high $(0.87)$ for plant height. For tunnel length, progeny means of $F_{3}$ lines varied from 25.8 to $82.4 \mathrm{~cm}$ similar to the range spanned by parents B52 and B73 $(31.1$ and $78.3 \mathrm{~cm}$, respectively). For plant height the range of $F_{3}$ lines (186.4-292.4 cm) considerably transgressed the range of parents B73 and B52 233.4 and $241.0 \mathrm{~cm}$, respectively) in both directions. Severe transgression of the parental range by the progenies violates one of the critical assumptions for Wright's estimator of the number of effective factors $(n)$ contributing to a polygenic trait. Hence, the number of effective factors was calculated for tunnel length only, resulting in an estimate of $n=4$.

Table 1 Means of parents B73 and B52, the $F_{2}$ generation, and $300 F_{3}$ lines derived from cross $\mathrm{B} 73 \times \mathrm{B} 52$ plus estimates of variance components and heritabilities $\left(h^{2}\right)$ among $\mathrm{F}_{3}$ lines for resistance against $2 \mathrm{ECB}$ (tunnel length) and plant height measured at two locations

\begin{tabular}{|c|c|c|c|}
\hline \multirow[b]{2}{*}{ Parameter } & \multirow[b]{2}{*}{$\begin{array}{l}\text { Entries } \\
\text { (number) }\end{array}$} & \multicolumn{2}{|l|}{ Trait } \\
\hline & & $\begin{array}{l}\text { Tunnel length } \\
(\mathrm{cm})\end{array}$ & $\begin{array}{l}\text { Plant height } \\
(\mathrm{cm})\end{array}$ \\
\hline \multicolumn{4}{|l|}{ Means } \\
\hline $\mathbf{P}_{1}(\mathrm{~B} 73)$ & 2 & $78.3 \pm 4.5 \ddagger$ & $233.4 \pm 4.9$ \\
\hline $\mathrm{P}_{2}(\mathrm{~B} 52)$ & 2 & $31.1 \pm 4.5$ & $241.0 \pm 4.9$ \\
\hline$\overline{\mathrm{P}} \dagger$ & 4 & $54.7 \pm 3.2$ & $237.2 \pm 3.5$ \\
\hline$F_{2}$ & 2 & $44.9 \pm 4.5$ & $276.7 \pm 4.9$ \\
\hline $\mathrm{F}_{3}$ lines & 300 & $50.7 \pm 0.6$ & $239.1 \pm 1.1$ \\
\hline \multicolumn{4}{|c|}{ Variance components $\left(\mathrm{F}_{3}\right.$ lines $)$} \\
\hline$\hat{\sigma}_{g}^{2}$ & & $69.27 \pm 9.54^{* *}$ & $317.84 \pm 30.11^{* * *}$ \\
\hline$\hat{\sigma}_{g}^{2} t$ & & $10.39 \pm 7.94$ & $27.49 \pm 8.98^{* * *}$ \\
\hline$\hat{\sigma}^{2}$ & & $141.43 \pm 8.75$ & $138.30 \pm 8.56$ \\
\hline \multicolumn{4}{|c|}{ Heritability $\left(\mathrm{F}_{3}\right.$ lines $)$} \\
\hline$h^{2}$ & & 0.63 & 0.87 \\
\hline$(90 \%$ C.I & & $(0.55,0.69)$ & $(0.84,0.89)$ \\
\hline
\end{tabular}

** Mean square associated with variance component estimate was significant at the 0.01 level of significance based on analysis of variance $F$-test.

$\dagger \bar{P}=$ mean of $P_{1}$ and $P_{2}$. $\ddagger$ Standard errors are attached.

$\S$ Confidence intervals of $h^{2}$ were calculated using the method by Knapp et al. (1985). 
Phenotypic correlations between tunnel length and plant height were highly significant for Ames $\left\langle\mathrm{r}_{p}=0.30^{* * *}\right)$ and for means across both locations $\left(r_{p}=0.25^{* *}\right)$. The genotypic correlation between the two traits was $r_{g}=0.29$ (S.E. $=0.07$ ).

\section{Associations between RFLP loci and agronomic traits}

In the combined analysis across locations, seven genomic regions located on chromosome arms $1 S, I L$, $2 S, 2 L, 3 L, 7 L$ and $10 L$ were found to significantly affect $2 \mathrm{ECB}$ resistance determined by tunnel length (Table 2). LOD scores at peaks of QTL likelihood maps ranged from 2.3 to 9.1 for the genomic regions on $1 S$ and $1 L$, respectively. B52 contributed the alleles for resistance against $2 \mathrm{ECB}$ at five of the seven putative QTLs, while alleles conferring resistance on $7 L$ and $10 L$ came from B73. Estimates of genetic effects revealed different types of gene action. The putative QTL mapping to chromosome arm $7 L$ displayed additive gene action $(d=0)$. Partial dominance $(-a<d<0)$ for resistance was found on chromosome arms $1 S, I L, 2 L$ and $10 L$. Overdominance $(d<-a)$ for resistance was found on $3 L$. The putative QTL on $2 S$ exhibited complete dominance for susceptibility $(d=a)$. In total, 38 per cent of the phenotypic variance was explained by the seven QTLs.

For tunnel length, results were largely consistent across locations (Fig. 2). If results from both locations gave evidence for the presence of a QTL, the maximum LOD score from the combined analysis was larger than LOD scores from individual locations. Examples are the putative QTLs for tunnel length on $1 S, 1 L, 2 S, 2 L, 3 L$ and $10 \mathrm{~L}$. If environment-specific QTLs occurred, as on chromosome arms $3 L, 6 L$ and $7 L$, the maximum LOD score of the combined analysis was considerably smaller than the greater LoD score of the two locations.

A comparison was made between the two homozygous marker classes of RFLP locus UMC33 on chromosome $I L$ that was tightly linked to the QTL explaining the largest fraction (16 per cent) of the phenotypic variance for tunnel length and having the largest additive effect $(a=5.7 \mathrm{~cm})$. The comparison revealed significant differences in the means $(P<0.01)$ and variances $(P<0.05)$ of the two homozygous marker classes for resistance against $2 \mathrm{ECB}$ (Fig. 3). Distribution of tunnel length in both marker classes and in their mixture did not show deviations from normality. The marker class homozygous for the B52 allele at locus $U M C 33$ had a significantly smaller mean $(\overline{\mathrm{x}}=45.4 \mathrm{~cm})$ and standard deviation (S.D. $=7.9 \mathrm{~cm}$ ) than the marker class homozygous for the $B 73$ allele $(\overline{\mathrm{x}}=56.4 \mathrm{~cm}$, S.D. $=10.2 \mathrm{~cm})$.

Three genomic regions on chromosome arms $1 S, 3 L$ and $9 L$ significantly affected plant height (Table 2 ) in the analyses for individual locations and combined across locations (Fig. 4). LOD scores at peaks of likelihood maps were high, ranging from 5.7 to 12.9 on $3 L$

Table 2 Biometrical parameters of putative QTLs significantly $†$ affecting resistance against $2 \mathrm{ECB}$ (tunnel length) and plant height estimated from phenotypic means of $300 \mathrm{~F}_{3}$ lines from cross $\mathrm{B} 73 \times \mathrm{B} 52$ grown at two locations

\begin{tabular}{|c|c|c|c|c|c|c|c|}
\hline Chromosome & $\begin{array}{l}\text { Flanking RFLP } \\
\text { markers of QTL }\end{array}$ & $\begin{array}{l}\text { Interval } \\
\text { length } \\
\text { (cM) }\end{array}$ & $\begin{array}{l}\text { Maximum } \\
\text { LoD } \\
\text { score }\end{array}$ & $\begin{array}{l}\text { Phenotypic } \\
\text { variance } \\
\text { explained }(\%)\end{array}$ & Additive $(\mathrm{cm})$ & Dominant & Direction§ \\
\hline \multicolumn{8}{|l|}{ Tunnel length } \\
\hline $1 S$ & $B N L 5.62-U M C 157$ & 33 & 2.3 & 3.4 & 1.7 & -0.8 & $\mathbf{P}_{1}$ \\
\hline $1 L$ & $U M C 33-U M C 128$ & 23 & 9.1 & 15.7 & 5.7 & -2.2 & $P_{1}$ \\
\hline $3 L$ & $U M C 175-B N L 5.37$ & 22 & 2.8 & 5.7 & 2.7 & -3.8 & $P_{1}$ \\
\hline $7 L$ & $B N L 14.07-U M C 59$ & 22 & 2.5 & 3.7 & 2.4 & 0.3 & $\mathbf{P}_{2}$ \\
\hline $10 L$ & UMC64-NPI303 & 9 & 3.0 & 4.9 & 2.7 & -2.9 & $\mathbf{P}_{2}$ \\
\hline Total & & & 24.8 & 38.0 & 20.8 & -9.6 & \\
\hline \multicolumn{8}{|l|}{ Plant height } \\
\hline Total $\ddagger$ & & & 37.0 & 63.1 & 35.0 & 16.5 & \\
\hline
\end{tabular}

$†$ Threshold for LoD score $T=2.2$.

†Estimates are based on a model fitting all putative QTLs simultaneously.

$\S$ Direction of the additive effect, i,e. if B73 $\left(\mathbf{P}_{1}\right)$ or B52 $\left(\mathrm{P}_{2}\right)$ alleles increased the value of the trait under study. 

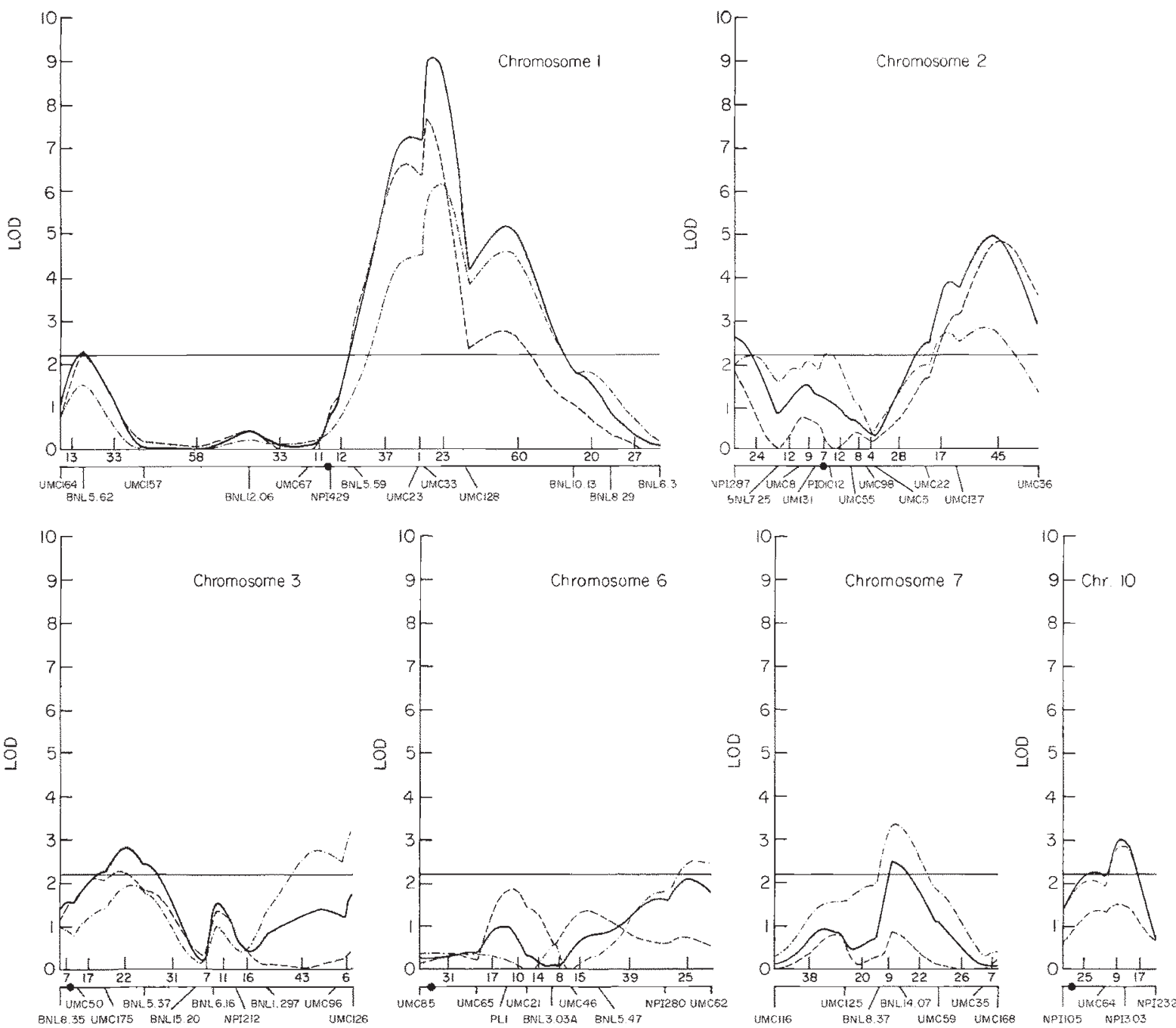

Fig. 2 QTL likelihood maps indicating LOD scores for tunnel length obtained from the combined analysis across two locations $(-)$ and separate analyses at Ames (-.--) and Ankeny (-- ) for chromosomes 1, 2, 3, 6, 7 and 10. A smooth curve was plotted through LOD scores spaced every $2 \mathrm{cM}$. The horizontal line at LOD $=2.2$ indicates the threshold for declaration of a QTL.

Fig. 3 Histogram of tunnel length for homozygous marker classes at locus $U M C 33$ and fitted underlying normal distributions with the respective mean and S.D. (ㅁ)B52. (a) B73.

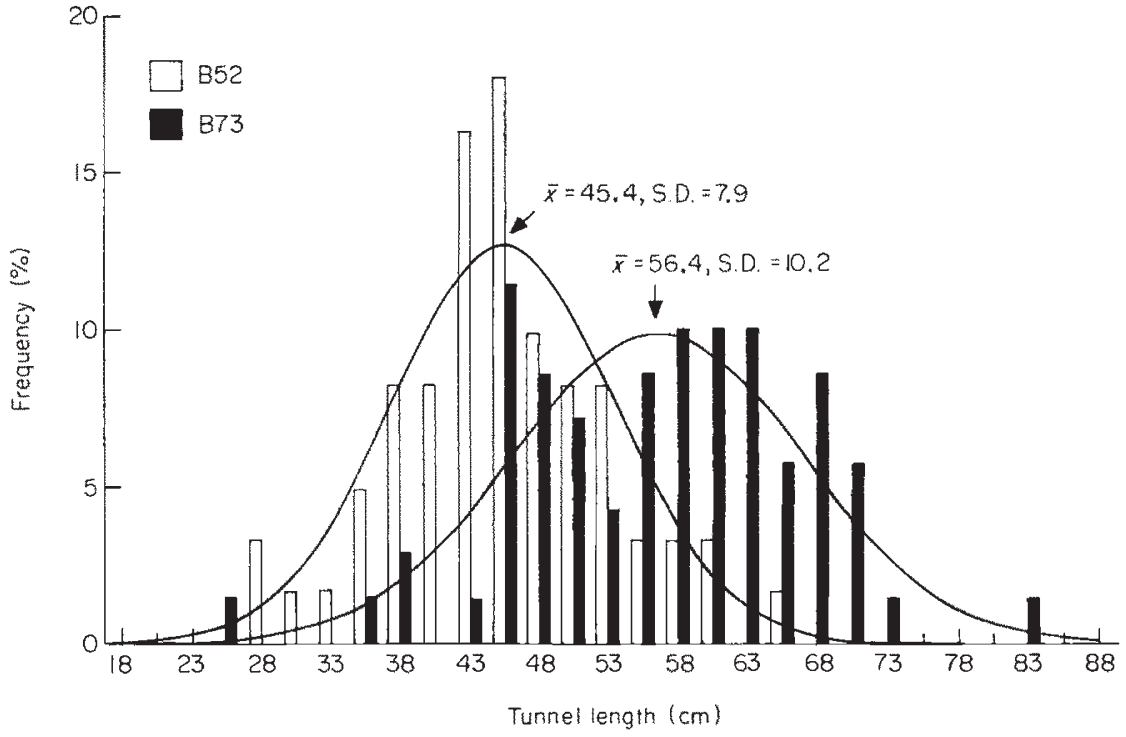



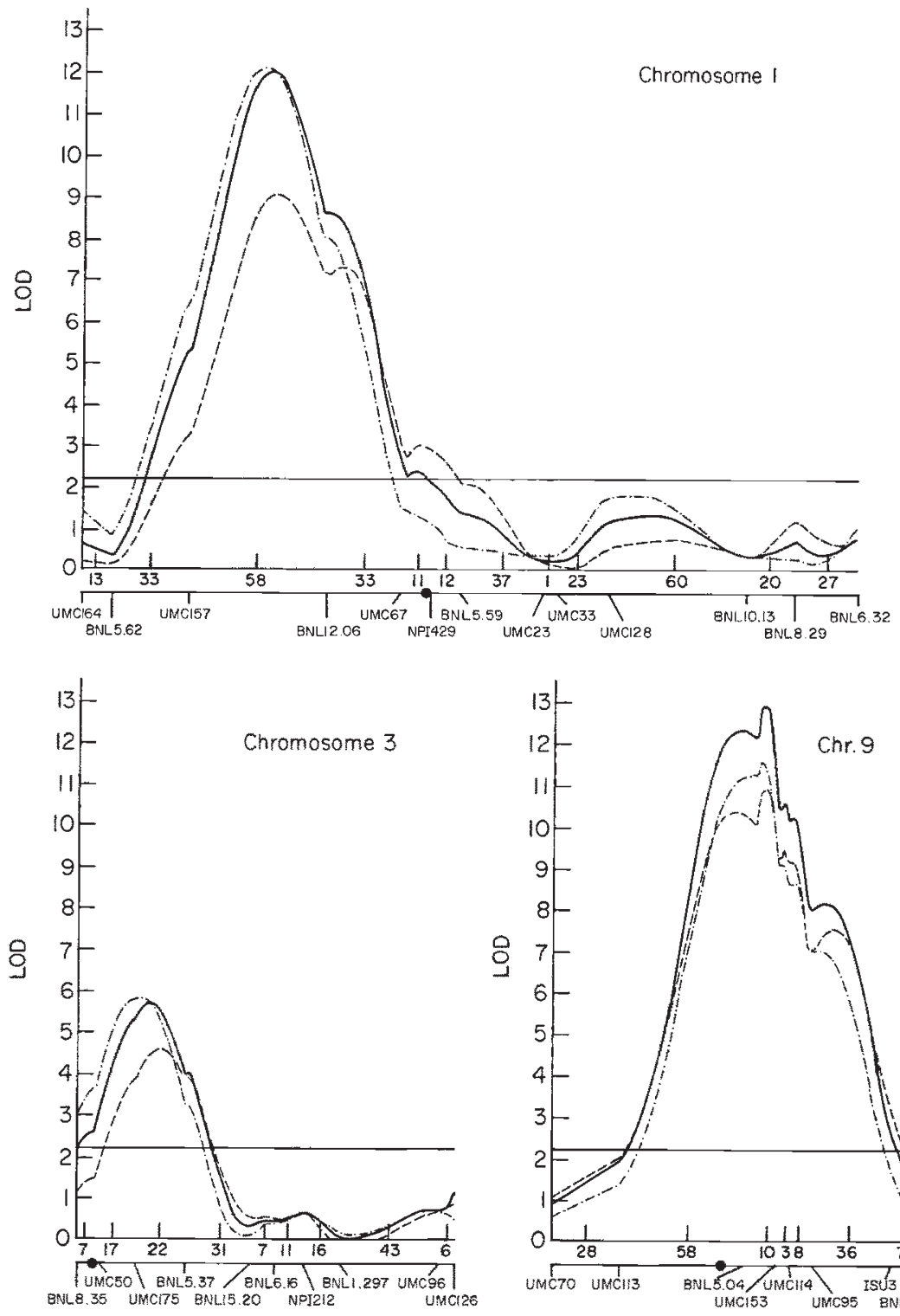

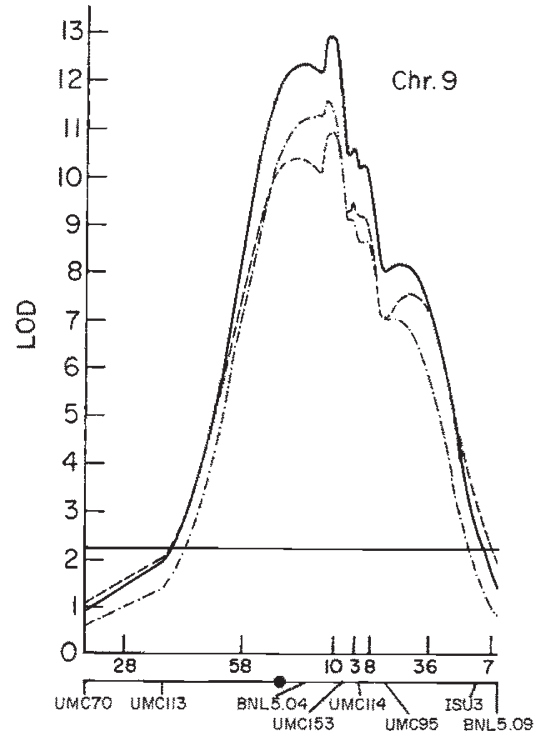

Fig. 4 QTL likelihood maps indicating LOD scores for plant height for chromosomes 1,3 and 9 . For further explanations see Fig. 2. and $9 L$, respectively. For the two putative QTLs on chromosome arms $I S$ and $9 L$, the alleles from B52 caused an increase in plant height. These two QTLs exhibited overdominance and partial dominance, whereas partial recessiveness $(-a<d<0)$ was found for the QTL on chromosome arm $3 L$. However, the putative QTLs on $3 L$ and $9 L$ had small estimates of dominance effects compared with estimates of additive effects. For plant height, 63 per cent of the total phenotypic variance was explained by the three putative QTLs.

To test if the putative QTLs for tunnel length were still detected after adjusting for plant height (tunnel length is limited by plant height), QTL mapping was performed on tunnel length per unit plant height. After the adjustment, four of the seven QTLs were still significant. Maximum LoD scores for the putative QTLs on $\left.7 L\left(L^{2 O D}\right)_{\text {max. }}=1.5\right)$ and $10 L\left(\operatorname{LOD}_{\max }=2.1\right)$ decreased below the critical threshold $(T=2.2)$, but there was still an indication for the presence of QTLs. On chromosome arm $3 L$, a QTL for both traits was observed in the same interval. After the adjustment, LoD scores decreased considerably $\left(\operatorname{LOD}_{\max .}=0.6\right)$ in this genomic region, suggesting that it was not a physiological mechanism of resistance against $2 \mathrm{ECB}$ but rather a physical limitation of tunnel length owing to shorter plant height that led to the significant QTL on $3 L$. 


\section{Two-way interactions}

For the 21 possible pairs of marker loci significantly associated with a putative QTL for tunnel length, little evidence for epistasis was found. Only one pair of marker loci (5 per cent), UMC137 (2L) and NP1303 (10L), exhibited significant digenic epistasis $(P=0.001)$. Most of this epistasis was attributable to a significant dominant $\times$ additive effect. $F$-tests for the remaining three contrasts were not significant. When testing the three possible pairs of marker loci that were significantly associated with a putative QTL for plant height, no significant epistatic effects were detected.

\section{Discussion}

We identified seven QTLs with significant effects on resistance against 2ECB. At five of these QTLs, resistance alleles originated from B52. It has to be stressed, however, that only those QTLs will be detected that explain a significant proportion of the phenotypic variance of the trait under study. For detection, a QTL must be tightly linked to adjacent marker loci and/or its genetic effect must be sufficiently large. No contributions to the genetic variance can be expected, if two loci with effects of similar size are closely linked in repulsion phase, or if the parents of a cross carry the same alleles. QTLs having exclusively epistatic but no additive or dominance effects would also remain undetected with our method of statistical analysis. Additionally, detection of QTLs is limited by the degree of polymorphism in a cross.

The number and location of genes involved in resistance against $2 \mathrm{ECB}$ were also investigated in a translocation study conducted by Onukogu et al. (1978). Translocation stocks were crossed onto the susceptible inbred lines Oh43 and W182E while B52 served as the source of resistance genes. The authors found seven chromosome arms $(I S, I L, 2 L, 3 S, 4 L, 5 S$ and $8 L)$ showing significant associations with resistance against $2 \mathrm{ECB}$. Three of them $(I L, I S$ and $2 L)$ were corroborated by our study as putative locations of QTLs for resistance against $2 \mathrm{ECB}$ contributed by $\mathrm{B} 52$. Moreover, the largest effects on resistance were found on $1 L$ and $2 L$ in both studies. As pointed out by Onukogu et al. (1978), translocation studies are confounded in that: (i) effects of linked genes cannot be distinguished and (ii) recessive or partially recessive genes will not be detected. Thus, the different materials and recessiveness of genes as found for the QTL on $2 S$ may explain some discrepancies between the two studies.

Using Wright's formula, the minimum number of effective factors $(n)$ was estimated to be four. This method provides an estimate of the actual number of genes only under the assumption of purely additive gene action and independent segregation of genes with equal effects (Wright, 1968). In addition, the parental inbreds need to represent the phenotypic extremes for the trait under study. Our results from QTL mapping indicate that these assumptions were not fulfilled so that dominant gene action, linked genes and incomplete association of genes of like effect in the parents probably resulted in underestimation of the number of genes involved in trait expression.

In conclusion, all three methods only provide an estimate for the minimum number of genes controlling a quantitative trait. QTL mapping, however, is definitely superior to the other two approaches. Firstly, smaller effects can be detected more readily and a relatively precise localization of the QTLs on the genome is possible. Secondly, QTL mapping allows biometrical parameters such as additive and dominance effects associated with individual QTLs to be estimated. Furthermore, linkage, if not too tight, should not bias the estimates.

Even though B73 is known to be highly susceptible to $2 \mathrm{ECB}$, the resistant allele at two of the seven putative QTLs for tunnel length was contributed by this inbred. Similar results were reported for the highly susceptible inbred $\mathrm{Oh} 43$ that positively contributed to resistance of the progenies in two sets of diallel crosses (Jennings et al., 1974). Scott et al. (1967) hypothesized that the resistance alleles of $\mathrm{Oh} 43$ only had an effect when crossed to a resistant inbred, suggesting the presence of epistasis. The significant dominant $\times$ additive epistatic interaction between UMC137 on $2 L$ and NPI3O3 on $10 L$ substantiated this conclusion. It might be speculated that resistance alleles found in elite lines are not as negatively correlated with agronomic performance as the alleles found in line B52 and, therefore, can be useful for production of improved source populations as a basis for selection.

As plant height might have a significant effect on tunnel length, the parents of our cross were chosen to be of similar height. Genes for plant height were still segregating in the $\mathrm{F}_{3}$ lines, as was obvious from the highly significant genotypic variance. The high LOD scores in three genomic regions provided strong evidence of significant QTLs for plant height.

On chromosome arm $3 L$, the likelihood peaks (i.e. the maximum LoD score) for the putative QTLs for tunnel length and plant height fell in the same marker interval. The B73 allele increased both plant height and tunnel length. QTL mapping results of tunnel length per unit plant height gave strong evidence of an interrelation of the genes regulating the two traits in this genomic region. The fact that only one marker interval was found to coincide for tunnel length and 
plant height agreed with the finding of a relatively small genotypic correlation $\left(r_{g}=0.29\right)$ for the two traits and disproved the presumption that a plant height QTL would automatically have an effect on resistance against 2ECB. The phenomenon of significant associations of molecular markers with more than one trait was also observed in other studies. Paterson et al. (1991) found overlapping marker intervals for the highly significantly correlated traits mass per fruit and soluble solids in tomato. Abler et al. (1991) observed the same for yield components and morphological traits. Explanations for these results are (i) pleiotropy or (ii) tight linkage. By using larger experimental populations or intermating of progenies it should be possible to distinguish between the two phenomena, but with an increase in population size only marginal earnings can be expected. An alternative strategy to disentangle the two possible causes for genetic trait correlations is the use of overlapping recombinant segments in a marker interval that has previously been identified to be significantly associated with the putative QTLs (Paterson $e t$ al., 1990).

The comparison of homozygous marker classes at UMC33 revealed significant differences in the variances for the two classes mainly because of one extreme value in each direction in the susceptible marker class (Fig. 3). The same observation was made for a number of markers and agronomic traits by Edwards et al. (1987). The increased variance for tunnel length of the homozygous marker class with the susceptible allele at $U M C 33$ could be a consequence of interactions between genes conferring resistance against $2 \mathrm{ECB}$ or a correlation between the mean and the variance. If the variance scales with the mean, a log transformation is usually applied. Results from QTL mapping with log-transformed mean values were almost identical to results with untransformed data.

As pointed out by Lande \& Thompson (1990), the proportion of the additive genetic variance that can be explained by the sum of all putative QTLs is proportional to the product of the heritability of the trait and the sample size. In addition, the fewer effective factors that contribute to the expression of a trait the larger becomes the proportion of the additive genetic variance that can be detected. In our study, these expectations were fully met. For tunnel length, $h^{2}$ was 0.63 and only 38 per cent of the phenotypic variance could be explained by fitting all seven QTLs simultaneously. Hence, about 60 per cent of the genetic variance for tunnel length could be accounted for. For plant height, $h^{2}$ was 0.87 and 63 per cent of the phenotypic variance, i.e. a total of 72 per cent of the genetic variance, could be explained by simultaneous fit of all three putative OTLs.
The use of $\mathrm{F}_{3}$ lines for QTL mapping has a number of advantages in comparison with other generations. Firstly, utilization of replicated progenies for phenotyping leads to an increase in power for testing hypotheses about genetic effects of QTLs (Knapp \& Bridges, 1990). Secondly, in contrast to backcross or fully homozygous progenies $(e . g$. recombinant inbreds or doubled haploids), $F_{3}$ lines allow dominance effects to be estimated. However, the power of testing for dominance effects is reduced in $\mathrm{F}_{3}$ lines compared with $\mathrm{F}_{2}$ individuals. This is because dominance effects contribute only half to the genotypic mean of the heterozygous marker class in the case of $\mathrm{F}_{3}$ lines but fully in the case of $F_{2}$ individuals (Mather \& Jinks, 1971). Consequently, precision of estimates of $d$ and epistatic interactions involving dominance effects $(a \times d, d \times a$, $d \times d)$ is also decreased. It seems likely that some epistatic interactions have remained undetected because of the use of $F_{3}$ lines and the limited resolution of the available statistical tests. The absence of epistatic interactions between the three putative QTLs for plant height as opposed to the significant epistasis inferred from the contrast $F_{2}+\bar{P}-2 \bar{F}_{3}$ suggested that the genetic variance not accounted for by the three putative QTLs for plant height is at least partly the result of genes with small or no main effects but considerable epistatic effects.

For the maize breeder, overdominance or dominance for resistance against $2 \mathrm{ECB}$ is the preferable type of gene action. If resistance of an inbred is fully expressed in the hybrid, the second parent of a cross can be chosen according to other criteria. Transmission of resistance from resistant inbreds to hybrid combinations was investigated by Scott et al. (1967). B52 transmitted its resistance in a mainly additive way. Jennings et al. (1974) found general combining ability (GCA) effects for resistance to be far more important than specific combining ability (SCA) effects in three diallel sets of crosses, which corroborated the preponderance of additive over dominant gene action. However, the estimate of the sum of dominance effects contributing to resistance to $2 \mathrm{ECB}$ obtained from diallel analysis may not be very accurate because dominance for susceptibility and resistance cancel each other. An example is the QTL for tunnel length on $2 S$ where complete dominance for susceptibility leads to reduced heterosis for resistance in the heterozygous progenies (Table 2). Our results indicate that a substantial proportion of genetic variation $(d \sim-1 / 2 a)$ results from dominant gene action.

Two QTLs, one for tunnel length on $3 L$ and one for plant height on $1 S$ exhibited overdominance. As pointed out by Edwards et al. (1987), the estimate of a genetic effect can indicate overdominance, while we 
are looking at two genes in repulsion phase with at least partial dominance in the same direction ('pseudo overdominance', Comstock \& Robinson, 1952). However, LOD scores for plant height on $1 S$ and tunnel length on $3 L$ did not indicate the presence of two distinguishable QTLs in the respective genomic regions. It was interesting that the QTL for tunnel length on $3 L$ exhibited overdominance while the QTL for plant height on $3 L$ was only partially dominant, which may indicate that it is not the same gene affecting plant height and resistance in this genomic region.

Stability of genotypes over environments is a major goal in plant breeding. Most QTLs found for tunnel length and plant height were consistent across locations, indicating that expression of genes conferring resistance against $2 \mathrm{ECB}$ was mainly independent of the environment. Only three significant QTLs were found for tunnel length at Ames (on $3 L, 6 L$ and $7 L$ ) that could not be detected at Ankeny. These findings were in contrast to results reported by Paterson et al. (1991), where a considerably smaller percentage of QTLs for soluble solids concentration and $\mathrm{pH}$ was shared by the two populations of tomato $\mathrm{F}_{3}$ lines grown in California and Israel. However, California and Israel represent much more diverse environments than Ames and Ankeny. The more pronounced sensitivity to environmental effects could also result from the employment of an interspecific instead of an intraspecific cross as well as from different environmental sensitivities of the respective traits. The non-significant or very small genotype by environment interaction observed in our study was an indicator for consistency of results across locations. For tunnel length, this finding was expected because this trait showed a high heritability in previous investigations (W. A. Russell, personal communication) and severe artificial infestation with larvae from the same insect population was carried out at both sites. It remains to be shown how well QTLs for resistance against 2ECB coincide in more diverse environments.

The detection of significant associations between genes conferring pest resistance and RFLP markers will be useful for a wide range of applications. For breeders it is important to obtain a more profound understanding of the inheritance of polygenic pest resistance and its interrelation with other agronomically important traits in order to develop improved breeding strategies. With the help of molecular markers, introgression and pyramiding of resistance genes from exotic or agronomically unacceptable germplasm may be accomplished with considerable savings in time. If QTLs exhibit significant epistatic interactions, marker-assisted selection should increase efficiency by facilitating the selection of genotypes with the favourable alleles at both loci. Moreover, if screening for resistant genotypes is very costly and time consuming as in the case of $2 \mathrm{ECB}$ resistance, the combination of marker-assisted and phenotypic selection should be superior to classical methods.

Further research is in progress to investigate the validity of our results for other populations and also to combine results from mapping of QTLs for resistance against $2 \mathrm{ECB}$ with those for other agronomically important traits. As described by Guthrie \& Russell (1989), four cycles of recurrent selection for improved resistance against $2 \mathrm{ECB}$ resulted in substantial reduction (24 per cent) of grain yield. For this reason, the testcross performance of the $300 \mathrm{~F}_{3}$ lines from cross $\mathrm{B} 73 \times \mathrm{B} 52$ is being evaluated and QTL mapping will be applied to elucidate the mechanisms that are responsible for the negative correlated response of resistance and yield potential.

\section{Acknowledgements}

This research was supported by grants from Northrup King and the Iowa State University Biotechnology Programme to M. Lee. This paper is dedicated to Professor Dr h. c. F. W. Schnell on the occasion of his 80 th birthday.

\section{References}

ABLER, B. S. B., EDWARDS, M. D. AND STUBER, C. W. 1991. Isoenzymatic identification of quantitative trait loci in crosses of elite maize inbreds. Crop Sci., 31, 267-274.

BERNATZKY, R. AND TANKSLEY, S. D. 1986. Toward a saturated linkage map in tomato based on isozymes and random cDNA sequences. Genetics, 112, 887-898.

BURR, B., BURR, F. A., THOMPSON, K. H., ALBERTSON, M. C. AND STUBER, C. W. 1988. Gene mapping with recombinant inbreds in maize. Genetics, 118, 519-526.

COCKerhaM, C. C. 1986. Modifications in estimating the number of genes for a quantitative character. Genetics, 114, 659-664.

COE, E. H., HOISINGTON, D. A. AND NEUfFER, M. G. 1990. Linkage map of corn (maize) (Zea mays L.) $(2 n=20)$. In: O'Brien, S. J. (ed.) Genetic Maps, 5th edn. Cold Spring Harbor Laboratory, Cold Spring Harbor, NY, pp. 6.39-6.67.

COMSTOCK, R. E. AND ROBINSON, H. F. 1952. Estimation of average dominance of genes. In: Gowen, J. W. (ed.) Heterosis. Iowa State College Press, Ames, IA, pp. 494-516.

EDWARDS, M. D., STUBER, C. W. AND WENDEL, J. F. 1987. Molecularmarker-facilitated investigations of quantitative-trait loci in maize. I. Numbers, genomic distribution and types of gene action. Genetics, 116, 113-125.

GRANER, A., JAHOOR, A., SCHONDELMAIER, J., SIEDLER, H., PILLEN, K., FISCHBECK, G., WENZEL, G. AND HERRMANN, R. G. 1991. 
Construction of an RFLP map of barley. Theor. Appl. Genet., 83, 250-256.

GUTHRIE, W. D. AND RUSSELL, W. A. 1989. Breeding methodologies and genetic basis of resistance in maize to the European corn borer. In: Toward Insect Resistant Maize for the Third World. Proceedings of the International Symposium on methodologies for developing host plant resistance to maize insects, Mexico, D.F.: CімMYT, Mexico, pp. 192-202.

GUTHRIE, W. D., RUSSELL, W. A., NEUMANN, F. L., REED, G. L. AND GRINDELAND, R. L. 1975. Yield losses in maize caused by different levels of infestation by second-brood European corn borers. Iowa State J. Res., 50, 239-253.

HALDANE, J. B. S. 1919. The combination of linkage values, and the calculation of distance between the loci of linked factors. J. Genet., 8, 299-309.

HALlAUER, A. R. AND MIRANDA FO, J. B. 1981. Quantitative Genetics in Maize Breeding. Iowa State University Press, Ames, IA.

HOLM, s. 1979. A simple sequentially rejective multiple test procedure. Scand. J. Stat., 6, 65-70.

JENNINGS, C. W., RUSSELL, W. A. AND GUTHRIE, W. D. 1974. Genetics of resistance in maize to first- and second-brood European corn borer. Crop Sci., 14, 394-398.

KEIM, P., DIERS, B. W., OLSON, T. C. AND SHOEMAKER, R. C. 1990. RFLP mapping in soybean: association between marker loci and variation in quantitative traits. Genetics, 126, $735-742$.

KNAPP, S. J. AND BRIDGES, w. C. 1990. Using molecular markers to estimate quantitative trait locus parameters: power and genetic variances for unreplicated and replicated progeny. Genetics, 126, 769-777.

KNAPP, S. J., BRIDGES, W. C. AND BIRKES, D. 1990. Mapping quantitative trait loci using molecular marker linkage maps. Theor. Appl. Genet., 79, 583-592.

KNAPP, S. J., STROUP, W. W. AND ROSS, w. M. 1985. Exact confidence intervals for heritability on a progeny mean basis. Crop Sci., 25, 192-194.

LANDE, R. 1981. The minimum number of genes contributing to quantitative variation between and within populations. Genetics, 99, 541-553.

LANDE, R. AND THOMPSON, R. 1990. Efficiency of markerassisted selection in the improvement of quantitative traits. Genetics, 124, 743-756.

LANDER, E. S. AND BotsteIN, D. 1989. Mapping Mendelian factors underlying quantitative traits using RFLP linkage maps. Genetics, 121, 185-199.

LANDER, E. S., GREEN, P., ABRAHAMSON, J., BARLOW, A., DALY, M. J., LINCOLN, S. E. AND NEWBURG, L. 1987. MAPMAKER: an interactive computer package for constructing primary genetic linkage maps of experimental and natural populations. Genomics, 1, 174-181.

LEE, M., GODSHALK, E, B., LAMKEY, K. R. AND WOODMAN, W. W. 1989. Associations of restriction fragment length polymorphisms among maize inbreds with agronomic performance of their crosses. Crop Sci., 29, 1067-1071.

LINCOLN, S. E. AND LANDER, E. S. 1990. Mapping genes controlling quantitative traits using MAPMAKER/QTL. Whitehead
Institute for Biomedical Research, Cambridge, MA. MATHER, K. AND JINKS, J. L. 1971. Biometrical Genetics, Chapman and Hall, London.

MODE, C. J. AND RoBinson, H. F. 1959. Pleiotropism and the genetic variance and covariance. Biometrics, 15, 518-537. NIENHU1S, J., HELENTJARIS, T., SLOCUM, M., RUGGERO, B. AND SCHAEFER, A. 1987. Restriction fragment length polymorphism analysis of loci associated with insect resistance in tomato. Crop Sci., 27, 797-803.

North Central Regional Extension Publication No. 327 , 1989. European corn borer. Development and Management. Iowa State University, Ames, IA.

ONUKOGU, F. A., GUTHRIE, W. D., RUSSELL, W. A., REED, G. L. AND ROBBINS, J. C. 1978. Location of genes that condition resistance in maize to sheath-collar feeding by second-generation European corn borers. J. Econ. Entomol., 71, 1-4.

PATERSON, A. H., DEVERNA, J. W., LANIN1, B. AND TANKSLEY, S. D. 1990. Fine mapping of quantitative trait loci using selected overlapping recombinant chromosomes, in an interspecies cross of tomato. Genetics, 124, 735-742.

PATERSON, A. H., DAMON, S., HEWITT, J. D., ZAMIR, D., RABINOWITCH, H. D., LINCOLN, S. E., LANDER, E. S. AND TANKSLEY, S. D, 1991. Mendelian factors underlying quantitative traits in tomato: comparison across species, generations, and environments. Genetics, 127, 181-197.

REITER, R. S., COORS, J. G., SUSSMAN, M. R. AND GABELMAN, W. H. 1991. Genetic analysis of tolerance to low-phosphorus stress in maize using restriction fragment length polymorphisms. Theor. Appl. Genet., 82, 561-568.

SAS Institute, 1988. SAS Language Guide for Personal Computers. Release 6.03 Edition, SAS Inst., Cary, NC.

SCOTT, G. E., GUTHRIE, W. D. AND PESHO, G. R. 1967. Effect of second-brood European corn borer infestation on 45 single-cross corn hybrids. Crop Sci., 7, 229-230.

SEARLE, S. R. 1971. Linear Models. Wiley, New York.

SHAPIRO, S. S. AND WILK, M. B. 1965. An analysis of variance test for normality (complete samples). Biometrika, 52, 591-611.

SLOCUM, M. K., FIGDORE, S. S., KENNARD, W. C., SUZUK1, J. Y. AND OSBORN, T. C. 1990. Linkage arrangement of restriction fragment length polymorphism loci in Brassica oleracea. Theor. Appl. Genet., 80, 57-64.

SNEDECOR, G. W. AND COCHRAN, W. G. 1967. Statistical Methods. Iowa State University Press, Ames, IA.

STUBER, C. W., EDWARDS, M. D. AND WENDEL, J. F. 1987. Molecular marker-facilitated investigations of quantitative trait loci in maize. II. Factors influencing yield and its component traits. Crop Sci., 27, 639-648.

THODAY, J. M. 1961. Location of polygenes. Nature, 191, 368-370.

WEBER, D. AND HELENTJARIS, T. 1989. Mapping RFLP loci in maize using B-A translocations. Genetics, 121, 583-590.

wEIR, B. S. 1990. Genetic Data Analysis. Sinauer, Sunderland, MA.

WRIGHT, s. 1968. Evolution and the Genetics of Populations. Vol. I. Genetics and Biometrical Foundations. University of Chicago Press, Chicago. 